\title{
An Attempt for Developing Albanian Anthropometric System within a Pilot Project
}

\author{
T. SPAHIU * ${ }^{1}$, E. SHEHI ${ }^{1}$, E. PIPERI ${ }^{2}$ \\ ${ }^{1}$ Faculty of Mechanical Engineering, Textile and Fashion Department, \\ Polytechnic University of Tirana, Tirana, Albania; \\ ${ }^{2}$ Faculty of Mechanical Engineering, Department of Production and Management, \\ Polytechnic University of Tirana, Tirana, Albania
}

DOI: $10.15221 / 16.269$ http://dx.doi.org/10.15221/16.269

\begin{abstract}
Anthropometric studies are a useful and accurate method for product design. In the apparel industry, anthropometric data are an important component for producing high quality garments. Different countries update their sizing systems used for garment design. In Albania, there are more than 35 years that there have not been conducted any anthropometric study. During these years, there have been several studies but they have aimed for small target groups. Moving into the full cycle production has become a necessity for Albanian garment industry in the last years. There are few firms working with their own brand for the home market, but they use different garment sizing systems. Thus, it is essential for Albanian companies operating in garment and footwear industry to use an Albanian sizing system. Updating anthropometric data will help garment and footwear companies to ensure good quality for their products.

The scope of this work is to show a methodology for body digitalization and to extract anthropometric data by the implementation of 3D technology. This is the first and biggest attempt for undertaking anthropometric measurements by using 3D technology in Albania.

A target group of 115 students aged $18-25$ years old were part of the study. All of them were female coming from different cities in Albania. Adapting of the scanning system Konica Minolta VIVID 910, for human body digitalization showed fast data captured and good quality of body digitalization. Advanced data manipulation and body dimensions extracting were done by using advanced software. This would open the way to a larger anthropometric study in the country.
\end{abstract}

Keywords: 3D body scanning, Human body modeling, 3D anthropometric data.

\section{Introduction}

Anthropometric studies are a useful and accurate method for product design. The advancements of 3D technology and computer graphics offers designers a fast and precise method for taking anthropometric measurements. Different countries undertake anthropometric studies every 15-20 years [1]. Developed countries around the word have undertaken anthropometric studies by using these advanced technology as Japan , SHBA, Holland, Italy [2], United Kingdom [3], Rumania [4], Spain [5], Thailand [6], etc. Among a wide variety of 3D scanners available in the market, those used commercially for digital measurements of human body can be divided in: laser scanning, white light scanning, passive methods, technologies based on other active sensors, TOF or touch sensors [7].

3D anthropometric data are very useful for assessing and improving the fit of different apparel products. The database of 3D anthropometric data can be used for assessing the effectiveness of shape wear [8], improving the fit of protective helmets [9], human body shape analysis [10] or shape variation [11].

3D body scanning systems as a technology for creating digital replicas of human body are equipped with programs for automatic extraction of anthropometric data, based on reference points. Based on anthropometric data extracted from 3D body scanning, parametric models has been created, which can be used for virtual garment design [12].

\section{Anthropometric studies in Albania}

Although different countries around the word update anthropometric data, there are more than 35 years there weren't done anthropometric studies in Albania. Necessity to have updated anthropometric data should not be neglected. The two biggest anthropometric studies undertaken in Albania were the first during 1971-1975 conducted by the Institute of the Light Industry and Food. Anthropometric data taken for 17000 persons participant in this study were used for developing sizing tables for clothing production, which were not existing before [13]. The second one started in 1989 
where 10000 persons participated in the study. Due to the political situation at that time, couldn't be completed [14]. The last studies undertaken in Albania has been aimed for small target group, with the main scope to enhancing garment fit.

The Textile \& Fashion Department, as a teaching unit at the Faculty of Mechanical Engineering, has played an important role in the process of taking anthropometric data in Albania. The attempts of the Textile \& Fashion Department to be part of the process for updating anthropometric data have been shown with small target groups. Anthropometric study in Albania will seek the cooperation of other stakeholders as Anthropologist, Mathematicians, Pattern maker, etc. Also, this would require a big financial support.

\section{The current situation of garment and footwear industry}

Garment and footwear industry is one of the main sector of the economy in Albania. This is related with the weight of exports and the number of employers. Before 90', the industry has operated in the conditions of a centralized economy. For this reason, the whole production chain from raw material up to the final production is realized within the country. Actually, Albania doesn't produce raw material and fabric for the textile industry, which has moved to garment and footwear production with ordered material. Different company operating in Albania produce garment and footwear for well known brands in other countries. One of the main challenges faced by Albanian garment \& footwear companies is changing by moving up in a full package service. This requires updating anthropometric data in Albania. Also, by improving and updating the services and technology used for garment and footwear production. Their scope to develop and market their own collections for home and foreign markets.

According to INSTAT there are 231 enterprise for textile manufacturing, 803 enterprise for apparel manufacturing and 289 enterprise for leather manufacturing and related products [15], compared to the last two years [16], [17], there is an increasing number of garment and footwear companies, given in Table 1. Recently there is a tendency form garment and footwear company to pass in a high level of production.

Table 1. Number of enterprises in the last 3 years.

\begin{tabular}{|c|c|c|c|}
\hline \multirow{2}{*}{ Enterprises } & \multicolumn{3}{|c|}{ Years } \\
\cline { 2 - 4 } & 2013 & 2014 & 2015 \\
\hline Manufacturing of textiles & 96 & 96 & 231 \\
\hline Manufacturing of wearing apparel & 706 & 748 & 803 \\
\hline Manufacturing of leather and related products & 197 & 229 & 289 \\
\hline
\end{tabular}

\section{Methodology}

The workflow of our system for full body scanning, advanced data manipulation and extracting anthropometric data is shown in Fig. 1.

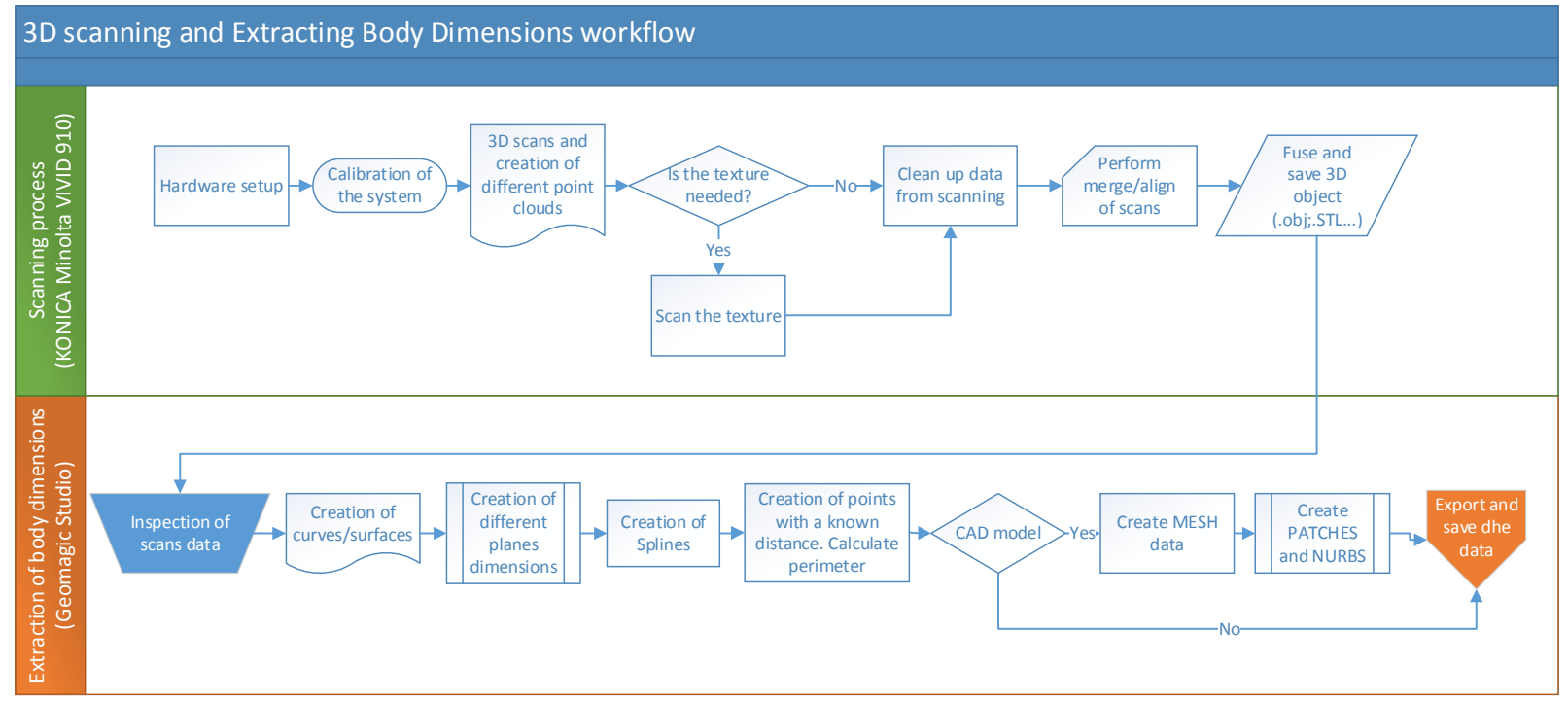

Fig. 1. Workflow from 3D body scanning and extracting anthropometric data. 


\subsection{Case study for body digitalization and extracting anthropometric data for $\mathbf{1 1 5}$ students}

Human body digitalization is an important process for taking accurate anthropometric data. Using 3D body technology for body digitalization comes as an effort of Textile \& Fashion Department, part in the process for taking anthropometric data in Albania. These efforts have resulted successfully even when they have been aimed for small target groups, by using the traditional anthropometric methods. But these methods are time consuming. Firstly adapting and using Konica Minolta VIVID 910 [18] for body digitalization, where manual and digital data comparison showed low values deviations between them [18]. For this reason, involving more people for body digitalization would be on interest to show a methodology for undertaking anthropometric data by using 3D scanning technology. Adaption of Konica Minolta VIVID 910 for body digitalization was applied for group comprising of 115 students, aged form $18-25$ years old. All the subjects chosen in the study were female coming from different cities in Albania. Subjects distribution by cities is given in Fig. 2, where the highest percentage is for students coming from Tirana. The only criteria used for selection has been their age. For every students are taken 20 anthropometric measurements. The procedure for taking anthropometric measurements is done according to the standard S SH EN ISO 7250-1:2010.

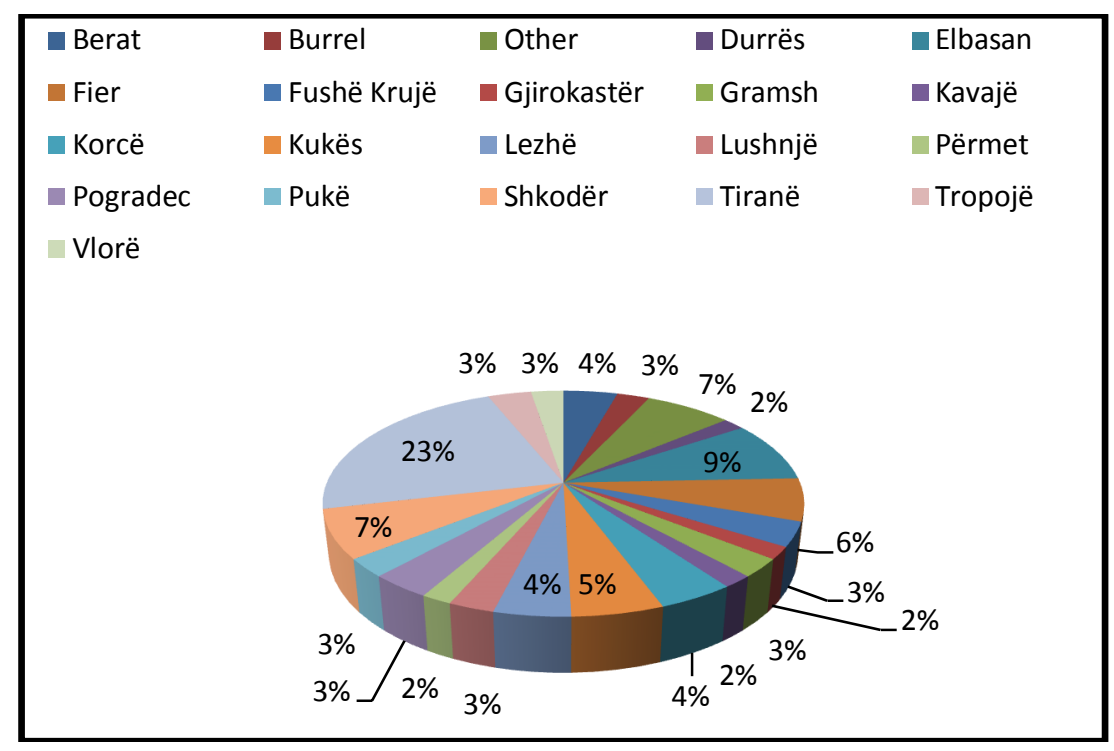

Fig. 2. Subjects distribution by cities in Albania

Through the procedure followed in this work can be extracted more anthropometric data. The standard comprises taking different anthropometric data, but not all these measurements can be used for clothing production. 20 anthropometric measurements were taken in consideration to be extracted, which are important for garment design and production. But, in the same time should be noted that there are anthropometric measurements which cannot be taken in the digital way. This is related with those measurement that should be taken in other standing position. From the experience of other countries, which have used full body scanning systems, mention the use of traditional method for taking anthropometric measurements. Before starting the scanning process, each one of the subjects is instructed about the procedure during the scanning process. This is a standard procedure used even during the process for full body scanning. Also all the participants were scanned wearing undergarments, since scan garments affects the body scan data [19].

Another objective of this work was foot digitalization. 35 subjects from the same target group used for body digitalization are selected and used for foot digitalization and taking anthropometric data according to the standard S SH ISO $9407: 2000$.

\subsection{Adapting Konica Minolta VIVID 910 for full body scanning}

\subsubsection{Pre-test methods}

Pre-test methods are followed to test and optimize the scanning process. This procedure is very important to determine the time needed for full body scanning. Different objects with different textures has been scanned. The preliminary results of the scanning process showed different characteristics, which were taken into account during the process of body scanning. Ethical explanation was done to ensure data privacy only for this study purpose. During the scanning process, the models had worn 
underwear, in white or light colors. Black colors showed problems during data capturing. The scanning process was done in the Laboratory of CAD/CAM and Technology of Garment Production in Polytechnic University of Tirana. The first and important step before starting the scanning process is system calibration. Taking into account the human body dimensions and foot dimensions Wide \& Middle lens are used during the scanning process. their characteristics are given in Table 2 and 3.

Table. 2.Characteristics during body scanning

\begin{tabular}{|l|l|}
\hline Lens & Wide \\
\hline Focal length & $\mathrm{f}=8 \mathrm{~mm}$ \\
\hline Measuring distance & $1200 \mathrm{~mm}$ \\
\hline Scan number & 16 \\
\hline Scanning time & $6 \mathrm{~min}$ \\
\hline
\end{tabular}

Table. 3. Characteristics during foot scanning

\begin{tabular}{|l|l|}
\hline \multicolumn{2}{|l|}{} \\
\hline Lens & Middle \\
\hline Focal length & $\mathrm{f}=14 \mathrm{~mm}$ \\
\hline Measuring distance & $1000 \mathrm{~mm}$ \\
\hline Scan number & 8 \\
\hline Scanning time & $3 \mathrm{~min}$ \\
\hline
\end{tabular}

Fig. 3 and 4 display views of the scanning system during body and foot scanning, as system setup and digital data captured for one single scan with the software Polygon Editing Tool Ver. 2.3 [20].
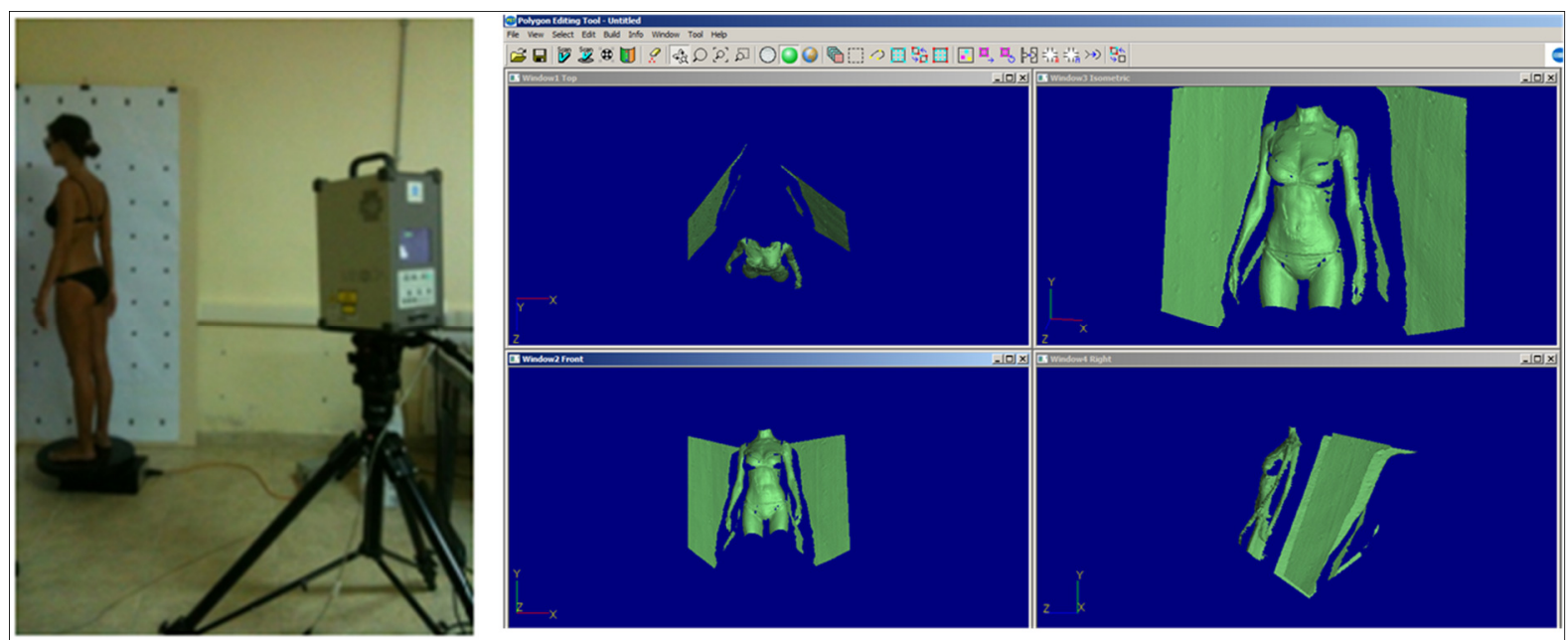

Fig. 3. Body scanning process: in the left during scanning process; in the right view of one single scan

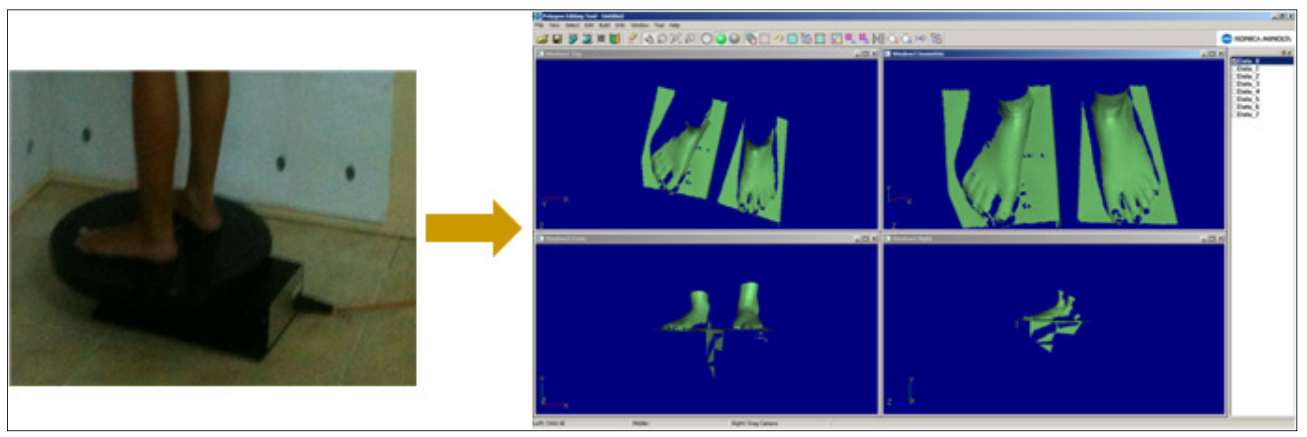

Fig. 4. Foot digitalization: in the left during scanning process; in the right view of one single scan. 


\subsection{Data analyzing and extracting body and foot dimensions}

In the process of Reverse Engineering, especially during the 3D object scanning, there are always imperfections during data capturing, even though using the most advanced scanning systems. An important step during 3D body modeling, is data analyzing. In different cases, point cloud data captured during the scanning process needs data cleaning of all unnecessary points or distortion during the scanning process. Filling holes, smoothness, etc., are some of the steps followed in this phase. Advanced software as Geomagic Studio ${ }^{\mathrm{TM}}$ and Geomagic Qualify ${ }^{\mathrm{TM}}$ [20], are used for data analyzing and extracting body dimensions. In Fig. 5 and 6 are shown steps during data analyzing of body and foot models.

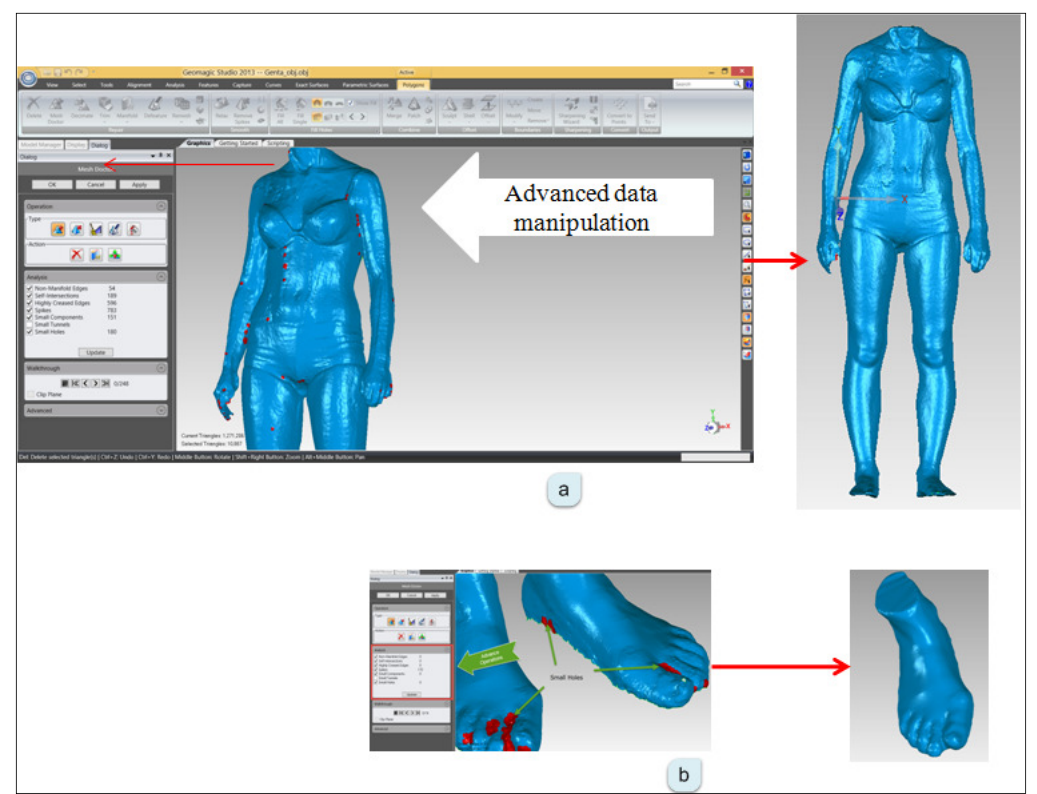

Fig. 5. Advanced data manipulation using Geomagic Studio ${ }^{T M}$ : a) for 3D body model and b) for 3D foot model.

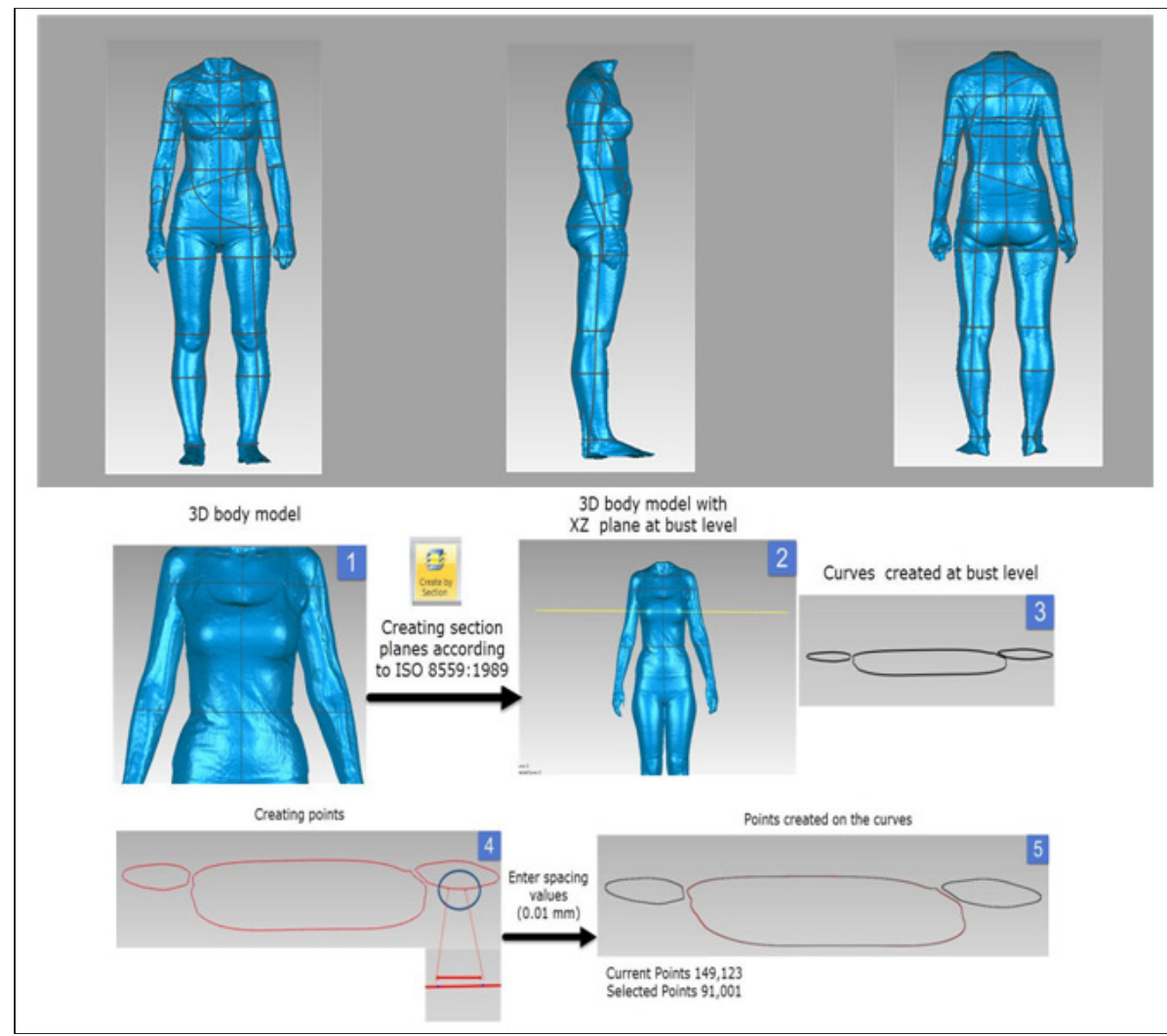

Fig. 6. Body dimensions according to the standard S SH EN ISO 7250-1:2010. 
Extracted anthropometric data are analyzed and chart data of some measurements for 20 years old category, are generated and given as follows in Fig. 7.
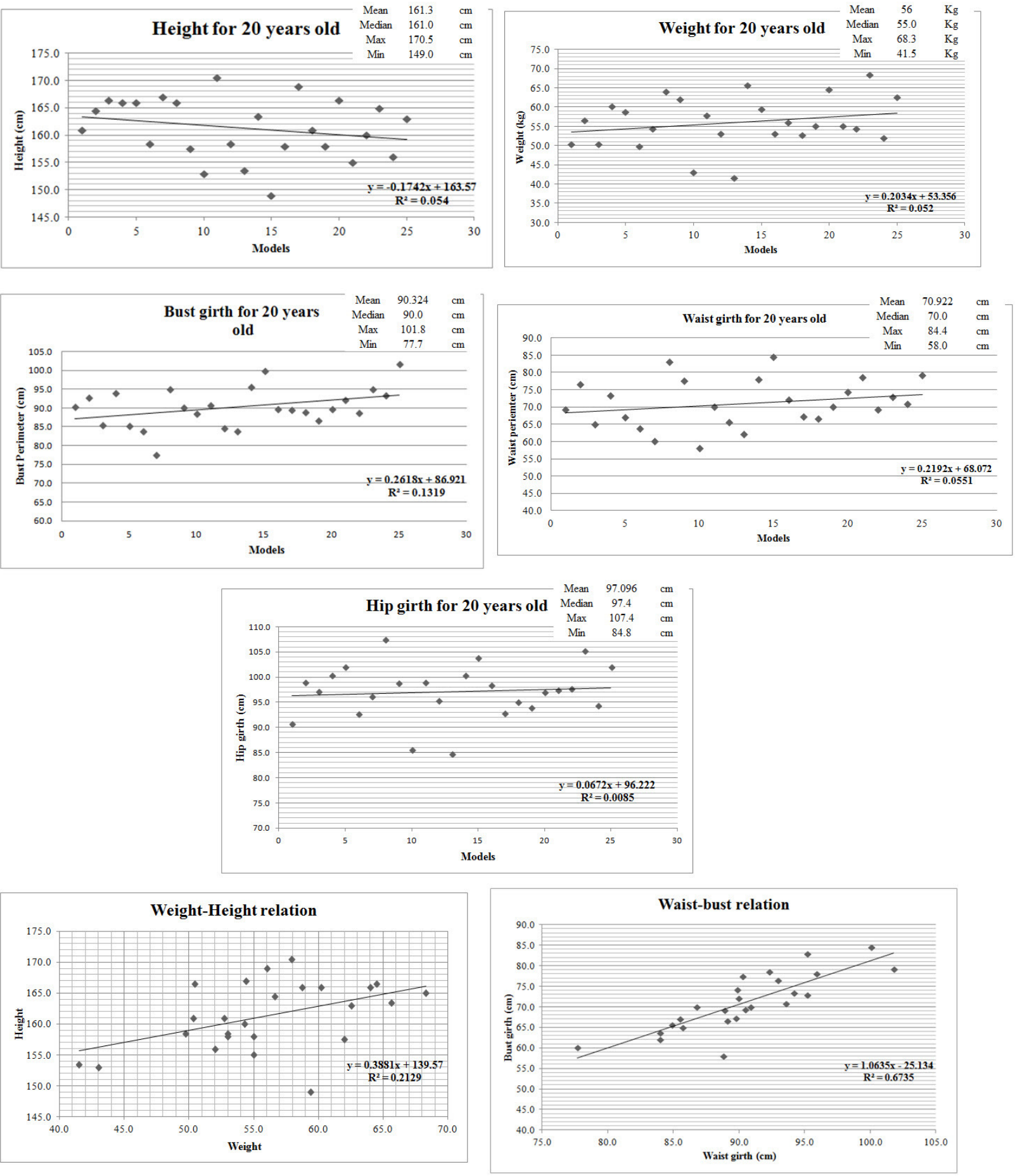

Fig. 7. Chart data of some measurements for 20 years old category.

3D foot models are imported in the Geomagic Qualify ${ }^{\mathrm{TM}}$ software and used for extracting anthropometric data. Followed procedure for extracting foot dimensions is realized according to the standard SH ISO 9407:1991(E). The main dimensions taken from 3D foot models are: length, width and perimeter of the foot. Data comparison of manual versus digital data is performed [21]. In Fig. 8 are shown steps during the process for taking foot dimensions according to the standard. 


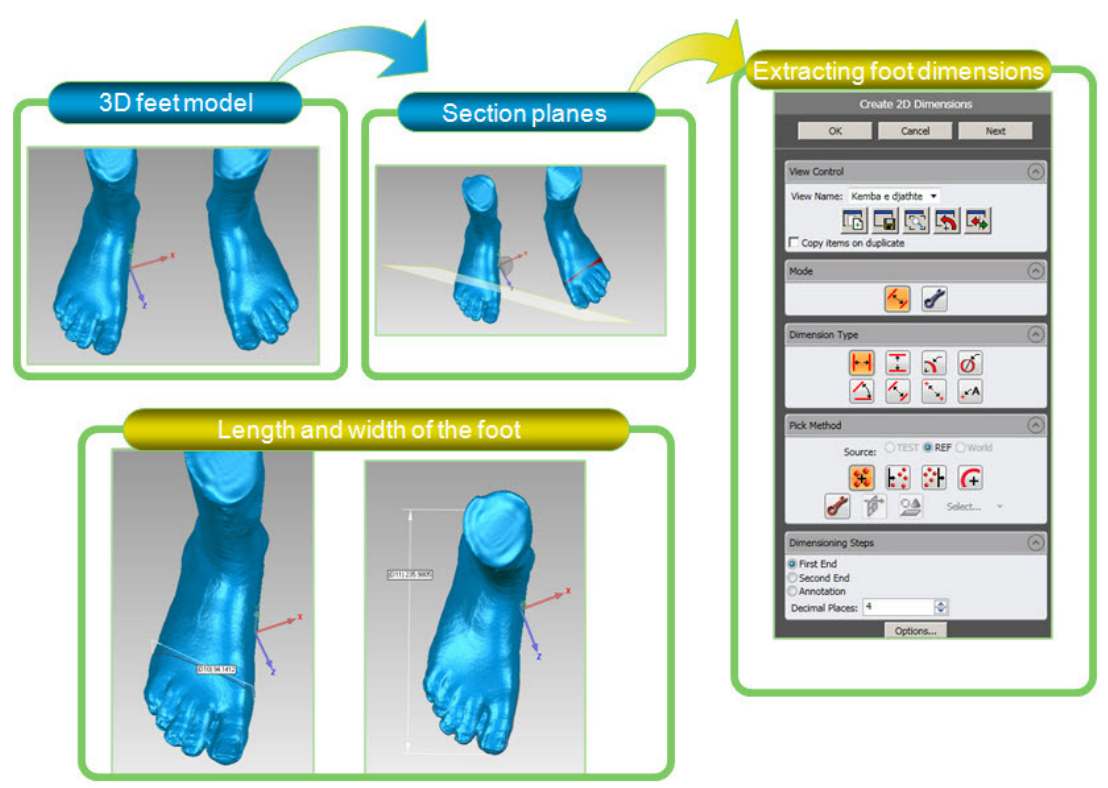

Fig. 8. Foot dimensions according to the standard S SH ISO 9407:2000.

\section{Results and discussions}

This study included the adaption and implementation of Konica Minolta VIVID 910 for body digitalization. 115 students aged $18-25$ years old were part of the study. All of them were female coming from different cities in Albania. It's worth mentioning that this is not a system for full body scanning. During the scanning process, different problems was encountered, as instability of the body models during the scanning process. Particular attention was shown during the scanning process. The scanning process needed longer time compared to the commercial one for body scanning, which affected digital data capturing. So the subjects were instructed to stay stable as much as possible. Breathing and human body movements affected digital data capturing. This resulted more evident for subjects more than $1.65 \mathrm{~m}$ body height.

Dedicated systems for body digitalization are equipped with software for automatic extraction of anthropometric measurements, compared with the system implemented in this work. For these reason, 3D body and foot models were exported in another software for advanced manipulation. As this is not an automatic procedure for taking anthropometric measurements, the reliability of this procedure is tested. Data comparison of the same measurement taken digitally and traditionally are performed [18]. Extracted anthropometric data are analyzed and chart data of some measurements for 20 years old category, are created.

Foot digitalization as another objective of this work, where 35 models used for body scanning were chosen for foot scanning. During the scanning process of the foot were encountered less problems compared with body scanning. This is related with the short time of the scanning process, only with one section, and the stability of the feet. A disadvantage of the implementation of these scanning systems for foot scanning was the difficulty for taking 3D digital information about the sole of the foot.

\section{Conclusions}

The adaption of 3D technology for body digitalization, advanced software for data manipulation and extracting anthropometric measurements showed the effectiveness for body digitalization. The work started with this target group shows a methodology for undertaking a national anthropometric study, which can be used for developing Albanian Anthropometric System. Anthropometric data processing will to create Albania Sizing System. This represents a novelty for apparel industry in the country. Creating Albanian Sizing System comes as a need from Albanian garment \& footwear to be used for the home market production. This will help garment and footwear companies to ensure good quality for their products. Other use of 3D body models are virtual footwear \& garment designing and simulation for companies operating in the country. 
In the following pictures (Fig. 9 and 10) are shown the preliminary results taken from the process of foot digitalization for a target group of 35 students and body digitalization part of the target group by 115 students.
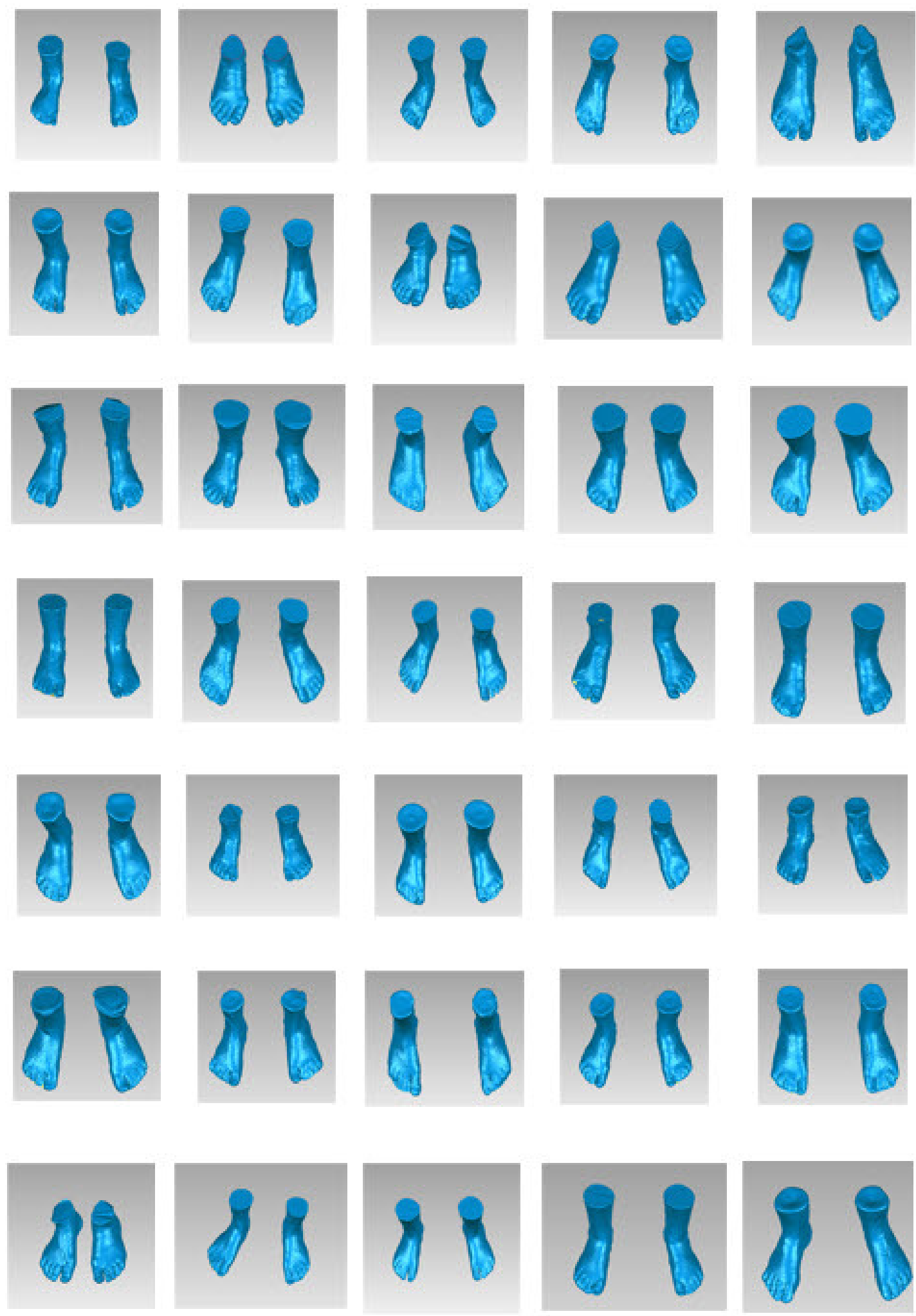

Fig. 9. 3D feet models 

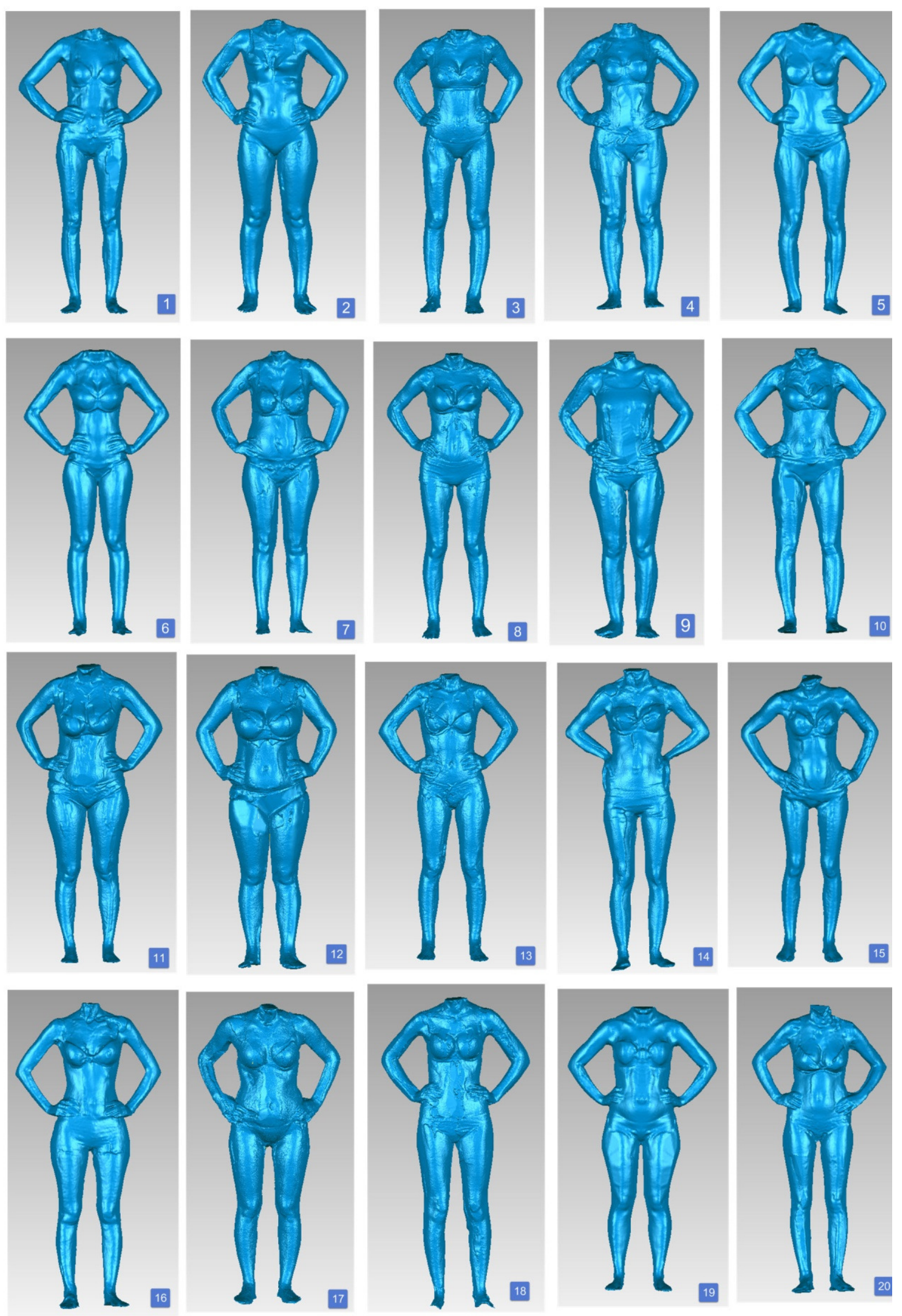

Fig. 10. 3D body models 


\section{References}

[1] D. Ujevic, Theoretical Aspects and Application of Croation Anthropometric System (CAS), University of Zagreb, Faculty of Textile Technology, Croatia, 2009.

[2] K. M. Robinette, S. Blackwell and H. Daanen, "CIVILIAN AMERICAN AND EUROPEAN SURFACE ANTHROPOMETRY RESOURCE," UNITED STATES AIR FORCE, 2002.

[3] J. P. Bougourd and P. C. Treleaven, "Capturing the Shape of a Nation: SizeUK".

[4] C. Niculescu, A. Salistean, S. Olaru, E. Filipescu, M. Avadanei and E. Danila, "3D BODY SCANNER ANTHROPOMETRIC INVESTIGATION OF THE ROMANIAN POPULATION AND ANTHROPOMETRIC DATA ASSESSMENT," in International Scientific Conference "Innovative solutions for sustainable development of textiles industry", Oradea, Romania, 2010.

[5] S. ALEMANY, J. C. González, B. Nácher, C. Soriano, C. Arnaiz and A. Heras, "Anthropometric survey of the Spanish female population aimed at the apparel industry," in International Conference on 3D Body Scanning Technologies, Lugano, Switzerland, 2010.

[6] S. CHAROENSIRIWATH and P. SRICHAIKUL, "Constructing Thailand's National Anthropometrics Database using 3D Body Scanning Technology," National Electronics and Computer Technology Center, Thailand.

[7] N. D'Apuzzo, "RECENT ADVANCES IN 3D FULL BODY SCANNING WITH APPLICATIONS TO FASHION AND APPAREL," in Optical 3-D Measurement Techniques IX, Vienna, Austria, 2009.

[8] L. Zhang, E. H. C. Shin and F. Baytar, "The use of 3D body scanning technology to assess the effectiveness of shapewear:changes in body shape," INTERNATIONAL JOURNAL OF FASHION DESIGN, TECHNOLOGY AND EDUCATION, 2016.

[9] S. Skals, T. Ellena, A. Subic and H. Mustafa, "Improving fit of bicycle helmet liners using 3D anthropometric data," International Journal of Industrial Ergonomics, vol. 55, pp. 86-95, 2016.

[10] M. Annichini, R. Arena, M. Fanini, M. Fattorel, D. Pavei, D. Tasson, V. Garro, C. Lovato and A. Giachetti, "Shape processing for digital anthropometry," in EUROGRAPHICS Workshop.

[11] C. Shu and L. Lepage, "Characterizing human shape variation using 3D anthropometric data," The Visual Computer, vol. 22, pp. 302-314, 2006.

[12] P. Sixiang, C. Chee-Kooi and A. H. W. Luximon, "Parametric Body Model Development," Computer Technology and Application, vol. 3, pp. 206-210, 2012.

[13] L. Hysa and S. F, Studimi i te dhenave antropometrike per nevoja te industrise se konfeksioneve, Tirane, Albania: Universiteti Shteteror i Tiranes, 1975.

[14] Ish Instituti i Industrise se Lehte dhe Ushqimore.

[15] M. MUÇA, F. SALA and L. GJINI, "BUSINESS REGISTER 2015," INSTAT, Tirana, Albania, 2016.

[16] G. Filipi, F. Sala and O. Kodra, "REGJISTRI I NDËRMARRJEVE EKONOMIKE 2013," INSTAT, Tirane, Albania, 2014.

[17] G. Filipi, F. Sala, L. Gjini, O. Kodra, E. Curumi and L. Milo, "REGJISTRI I NDËRMARRJEVE EKONOMIKE 2014," INSTAT, Tirane, Albania, 2015.

[18] NON-CONTACT 3D DIGITIZER VIVID 910/VI 910 Instruction Manual (HARDWARE), Konica Minolta .

[19] T. Spahiu, E. Shehi and E. Piperi, "Extracting body dimensions from 3D body scanning," in 6-th INTERNATIONAL CONFERENCE OF TEXTILE, Tirana, Albania, 2014.

[20] G.-E. Kim, K. LaBat, E. Bye, M. Sohn and K. Ryan, "A study of scan garment accuracy and reliability," The Journal of The Textile Institute, Taylor \& Fransis, vol. 106, no. 8, pp. 853-861, 2014.

[21] Polygon Editing Tool Instruction Manual, Konica Minolta .

[22] "3D Systems," September 2016. [Online]. Available: http://www.geomagic.com.

[23] T. Spahiu, E. Shehi, L. M. Galantucci, J. Kaçani and E. Piperi, "3D Low Cost Scanning Systems for extracting foot dimensions," UNIVERSI - International Journal of Education, Science, Technology, Innovation, Health and Environment, vol. 1, no. 3, pp. 48-55, 2015. 